Intergroup Coordination

Groups Outperform Individuals in Tacit Coordination by Using Consensual and Disjunctive Salience

Christopher R. Chartier, Ashland University

Susanne Abele, Miami University

Please address correspondence to:

Christopher R. Chartier

Department of Psychology

Ashland University

401 College Avenue

Ashland, $\mathrm{OH} 44805$

cchartie@ashland.edu 
Groups Outperform Individuals in Tacit Coordination by Using Consensual and Disjunctive Salience

\begin{abstract}
Tacit coordination between individuals has received considerable research attention (Mehta, Starmer \& Sugden, 1994; Abele, \& Stasser, 2008). However, groups often must coordinate tacitly with other groups, and such intergroup coordination has been rarely studied. In three experiments, we found that interacting groups are more successful at coordinating tacitly than are individuals. This advantage is driven by two types of coordination salience that are uniquely derived from groups deliberating and making collective responses. Consensual salience occurs when groups select a response because a majority of members support it. Majorities efficiently identify popular response tendencies (i.e., focal points) and thereby increase the chances of matching other groups' responses. Disjunctive salience occurs when at least one member of a group suggests a focal point. We propose that focal points are often demonstratively evident when mentioned, and if proposed by any group member, are likely to be adopted as the group response.
\end{abstract}

Keywords: tacit coordination; interdependent decision making; group processes 
Groups Outperform Individuals in Tacit Coordination by Using Consensual and Disjunctive Salience

Social actors frequently encounter situations that demand coordination of actions with others. Friends attempting to meet in a crowded concert venue have to correctly anticipate where each is likely to go. Greeting rituals with family and friends present a multitude of possible actions - handshake, hug, or kiss - and failure to coordinate is embarrassing at a minimum. Potentially more disastrous are failures of drivers to coordinate effectively on the roadways, which can lead to accidents. These situations are relatively easy to navigate if parties communicate about possible courses of action. Since all parties involved first and foremost want to coordinate, disagreements are unlikely to arise and are easily overcome if discussed. However, communication is often awkward and impractical, and sometimes it is impossible. Cell phones can be forgotten at home, lack reception, or run out of battery power. An anticipated opportunity to chat with one's partner can be unexpectedly missed. An assumption that two people are "on the same page" can be made in error. Under such conditions, coordination can still be achieved tacitly, through mutually held understandings and expectations. Problems of tacit coordination typically cannot be unilaterally solved by reason or logic and even wellintentioned and well-acquainted actors, such as romantic partners, are not universally successful in their attempts at coordinating tacitly (Chartier \& Abele, 2015). Of the dozens of potential meeting places in a park, how can two friends hope to select the same one? Indeed, from an economic perspective, the behavioral options are often indistinguishable in payoffs, and hence the many possible solutions are equally attractive to the parties involved. The friends want to meet and whether they meet by the concession stand or the fountain matters little. In game theoretic terms, a problem can be said to have many pure strategy Nash-equilibria, or patterns of 
responses that once arrived at, leave no party with an incentive to unilaterally change their decision (Nash, 1950).

Thomas Schelling (1960) proposed that options in coordination problems are often distinguishable by label even if they do not differ in attractiveness, and that these labels differ in terms of salience to interacting partners as potential solutions to the coordination problem. His informal investigations supported this notion by demonstrating that individuals do not respond randomly when trying to coordinate, but opt for salient options termed focal points. For example, he asked a convenience sample where and at what time of day they would meet a stranger who was also trying to meet them in New York City. A majority picked Grand Central Station and virtually all chose noon. Therefore, grand Central Station at noon is a focal point, or effective solution, to this particular coordination problem. Mehta, Starmer, and Sugden (1994) investigated the concept of focal points more systematically and demonstrated that coordination was far more likely when interacting parties had the explicit goal of matching, as opposed to simply responding with their idiosyncratic preferences. Therefore, success indeed depends on the appeal of focal points rather than mere coincidence or shared preferences. There is more to focal points than mere preferential majority independent of the coordination problem. People consider them to be reasonable responses to coordination problems.

These early investigations of tacit coordination focused on coordination between individuals; intragroup coordination. But social situations often require coordination between groups; intergroup coordination. Where exactly should we meet the Jones's for our picnic in the park? What hours should our store be open during the holidays to dovetail with other local businesses? The current work develops the theoretical underpinnings of differential performance in intergroup and intragroup tacit coordination, measures the tacit coordination 
performance of interacting groups relative to interacting individuals, and tracks the processes underlying intergroup tacit coordination decisions.

Groups outperform individuals at many problem solving tasks (Laughlin \& Ellis, 1986; Hill, 1982). There are, of course, counter-examples where groups actually perform quite poorly. Examples include cases of hidden profiles, in which groups focus on information all members know to the detriment of unique and critical information that only one member knows (e.g. Stasser \& Titus, 2003) and the consideration of base rates in probabilistic reasoning, where groups seem to magnify biases and errors in judgment (Hinsz, Tindale, \& Nagao, 2008). Kerr and Tindale (2004) suggest that this inconsistent performance can be partially explained by the fact that groups focus on cognitions that members share in common to the relative exclusion of cognitions that are not shared by members. "Social sharedness" can either help or hinder a group's decision making process depending on the specifics of the problem faced (Tindale, Smith, Dykema-Engblade, \& Kluwe, 2012). We contend that tacit coordination is a domain in which groups will benefit from their reliance on socially shared cognitions. In scenarios demanding tacit coordination, relying on socially shared cognitions should be beneficial because successful coordination often requires the actors to match the actions of others; a purely consensual process with no objectively "correct" answer. There is some initial evidence to suggest that this may be the case. Feri, Irlenbusch, and Sutter (2010) showed that groups, compared to individuals, converged more quickly on pay-off dominant solutions in coordination games where options differ in terms of actor outcomes. Their findings are consistent with the cumulative evidence that teams are more responsive to economic incentives than are individuals (see, e.g., Bornstein, Kugler, \& Ziegelmeyer, 2004). However, as mentioned before, in many coordination situations, the response options do not differ in attractiveness and choosing any 
common response is the primary concern. Thus, we focused on tasks that more directly model social situations such as the "meeting" problem, in which options are distinguishable by labels but not by payoffs. We hypothesize that interacting groups will outperform interacting individuals in tacit coordination based on two predicted group-level mechanisms for detecting focal points: consensual salience and disjunctive salience. Consensual salience is born of a pattern of majority influence in small groups. Disjunctive salience rests on the idea that focal points have demonstrative appeal, and will be influential once considered.

\section{Consensual Salience}

In a matching coordination task, the successful response is that which others predominantly select. Groups should be better able than individuals to identify such population level consensus by sampling the response tendencies of their members and checking for a dominant or modal response. We hypothesize that if an option is initially preferred by a majority of group members, it will be selected as the group's decision. In terms of social decision schemes, this process would yield a "majority-wins" scheme (Davis, 1973; Laughlin, 1999; Stasser, 1999). Such a pattern would echo classic findings on majority influence and attitude polarization in small groups (Moscovici \& Zavalloni, 1969; Myers \& Lamm, 1976). Operationally, a focal point is the most popular response in a target population and majority processes should amplify the popularity of the most popular response. To demonstrate, suppose $80 \%$ of individuals in a particular population prefer meeting at Grand Central Station, while 20\% prefer meeting at Times Square. There is a $90 \%$ chance that a group of three randomly drawn from this population will have a majority who prefer Grand Central Station, substantially increasing the odds that two groups, as opposed to two individuals, will successfully meet in New York City if a majority wins decision scheme is followed. There are however ample 
counter-examples in which "majority-wins" social decision schemes are not followed, such as in cases where problems have demonstrably correct solutions (Laughlin, 1980; Laughlin, 1999). Thus, the two open questions regarding the consensual salience hypothesis are will groups typically follow a majority-wins decision scheme in this domain, and if so, will this be to the benefit of the group?

\section{Disjunctive Salience}

Groups may also benefit from a distinct, yet not mutually exclusive process, which we term disjunctive salience. If one member of a group suggests a focal point, then others may experience a "Eureka"-like feeling due to its intuitive appeal. For example, Mehta, et al. (1994) asked individuals to name a flower. When simply picking a flower, $35 \%$ responded rose. This was the most popular response. When attempting to match another randomly chosen individual, $67 \%$ responded rose, suggesting that many who would not have chosen rose if simply picking were able to correctly recognize that it would be a popular matching option. The concept of disjunctive salience implies that, if any group member mentions the focal point (rose in the foregoing example), the group will likely select it. A member may initially prefer lily, but think to themselves something along the lines of "now that you mention it, rose is a really great and obvious pick!" In this sense, identifying a focal point is a disjunctive task because the most effective group member determines the group success (Steiner, 1972). Just as when a group of friends is searching for the last puzzle piece that seems to have been lost in the house, the group succeeds if any single member succeeds. In terms of social decision schemes, the proposed process is captured by a "truth-wins" scheme (Davis, 1973; Laughlin, 1999; Stasser, 1999). Assume that $80 \%$ of the population prefers rose as the best coordinating response. There is a $99 \%$ chance that at least one member of a group of three will prefer rose. If rose-proponents 
mention this preference, and others are convinced that it is the best option, group performance will benefit.

Both of these processes should lead to more convergence in group responses compared to individual responses. In Experiment 1 we compared the tacit coordination performance of groups and individuals. In Experiment 2 we compared group responses to the responses of the individuals that comprised the groups in order to more directly test consensual and disjunctive salience as group processes involved in tacit coordination decisions. In Experiment 3 we assess the impact of coordinating with a group, independent of coordinating as a group.

\section{Experiment 1}

As a first test of these ideas we had both individuals and three person groups engage in a series of tacit coordination matching tasks. We then compared group and individual performance. We hypothesized that successful coordination would be more frequent when two groups were interacting than when two individuals were. Additionally, we compared the performance of groups to that of nominal groups which are groups in name only, comprised of randomly selected individuals with a strict "majority-wins" decision scheme applied.

\section{Method}

\section{Participants.}

Participants were 132 students in Introductory Psychology courses at a North American university. They participated in exchange for partial fulfillment of a course requirement. Participants were randomly assigned to participate either as individuals or in groups of three, yielding 66 individuals, 22 groups, and 22 nominal groups.

\section{Procedure.}


All procedures for these experiments were approved by the Institutional Review Board prior to the beginning of data collection, and all participants provided informed consent before participating. Participants in the individual condition were seated in private cubicles and given a sheet with instructions and the individual version of the coordination task. The task was made up of 25 coordination matching games intended to model typical "meeting" style coordination problems (Table 1). Participants were instructed to match a randomly selected other participant who was given identical instructions on as many of the 25 coordination items as they could. Specifically, they were told "your objective is to give the same answer as the person with whom you have been paired. The person that you have been paired with was given exactly the same instructions - namely that his or her objective is to give the same answer as you do."

Participants in the group condition were randomly assigned to groups of three. Group members convened around a central meeting table, and were given instructions. Groups were told that their task was to match a randomly selected other group on as many of the 25 coordination items as they could. Hence, group instructions were identical to individual instructions, with the exception that they would be paired up with a randomly selected group rather than individual, and asked to discuss each item in order to arrive at a single collective response. We incentivized performance for both groups and individuals. For each item that was successfully matched, each individual or group member would earn an entry into a lottery from which we drew three winners of twenty dollars at the conclusion of the study.

\section{Results}


Predicted coordination. The likelihood of coordination success can be calculated from the pattern of responses exhibited by groups and individuals. The coordination index, $c$, is the probability that any two randomly selected actors will give the same response (Mehta, Starmer, \& Sugden, 1994). Let $N$ be the number of actors in the sample from which responses are being sampled, and let $k$ be the number of distinct responses chosen by those actors. Also, let $m_{1}, \ldots$, $m_{k}$ be the number of actors giving each of the responses $1, \ldots, k$. Then, for each of the items on a coordination task, the coordination index is given by, $c=\sum_{i-1}^{k}\left(\frac{m_{1}}{N}\right)\left(\frac{m_{1}-1}{N-1}\right)$. We adjusted the typical calculation of $c$ to instead give the probability that a specific actor (group or individual) would succeed in matching a randomly selected other actor on each specific item. This more granular coordination index, $g c$, allows us to assess the coordination performance of each actor on each item, as opposed to the overall sample performance on each item, as is the case with the traditional index $c$. It is computed by dividing the number of other actors that gave the same response to the item, not including the actor in question, by the total number of other actors, $g c=\left(\frac{m_{1}-1}{N-1}\right)$. We conducted an independent samples t-test comparing group success to individual success, as measured by the average $g c$ for each actor. This test revealed a significant difference, such that groups $(M=.591, S D=.036)$ outperformed individuals $(M=.433, S D=$ $.071), t(86)=10.06, p<.001, \eta^{2}=.54,95 \% C I$ of difference $[.127, .190]$ (Figure 1). A straightforward interpretation of this result is that two randomly chosen groups are expected to match on a randomly chosen item $59 \%$ of the time whereas individuals had only a $43 \%$ chance of matching with another randomly chosen individual. 
Comparison to Nominal Groups. We sought to further address the magnitude of the intergroup advantage by comparing the performance of the groups in Experiment 1 to nominal groups created by randomly assigning the individuals in the experiment to groups, and applying a strict "majority-wins" decision scheme to arrive at their "group" decision. Similar comparisons are often employed in the group process literature in domains such as brainstorming and social loafing (Diehl \& Stroebe, 1987; Lattané, Williams \& Harkins, 1979). For each item, if a response had been selected by a majority of individuals in the nominal group, we selected that as the nominal group response. For items without majorities, we used a random number generator to select the nominal group response from among the three individual responses. We then calculated the likelihood of success on each item for each nominal group just as it was calculated for individuals and actual groups. An independent samples t-test comparing actual group predicted success $(M=.591, S D=.036)$ to nominal group predicted success $(M=.505, S D=$ .041 ) revealed a significant actual group advantage, $t(42)=7.36, p<.001, \eta^{2}=.58,95 \% C I$ of difference $[.062, .109]$ (Figure 1). This result suggests that groups outperform what one would expect from simple aggregation of individual responses. This result also hints at the likely effectiveness of disjunctive salience to produce successful intergroup tacit coordination. One key advantage that actual groups may have over nominal groups is in "breaking ties" in the direction of the population level focal point. We tested this hypothesis, and other process hypotheses, more directly in Experiment 2.

\section{Experiment 2}

Experiment 1 established the group advantage in matching coordination. Experiment 2 was designed to explore the hypothesized mechanisms underlying this advantage. In Experiment 2, participants first completed the tacit coordination task as individuals. Subsequently, they 
completed the task as members of three-person groups. This procedure allows comparison of group responses to the responses of the individuals that comprise the group and for the creation of clearly defined nominal groups created out of the individual responses within each group. The consensual salience hypothesis predicts that the response option that is chosen by a majority of group members as individuals will become the group response and that majority responses will be more likely to result in successful coordination than minority responses. The disjunctive salience hypothesis predicts that, when no majority exists, groups are likely to select the focal point if one member of the group selected the focal point as an individual.

\section{Method}

\section{Participants.}

Participants were 63 students in Introductory Psychology courses at a North American university. They participated in exchange for partial fulfillment of a course requirement. They first participated as individuals and then in groups of three.

\section{Procedure.}

All participants were given the individual version of the coordination task, which was identical to that used in Experiment 1. Participants' response sheets were inconspicuously marked in order to later allow the matching of individual responses to the responses of their groups for process analyses. After participants had completed the individual coordination task, they were randomly assigned to groups of three and given the same group coordination instructions as in Experiment 1. We incentivized performance at both the individual and group stage. For each item that was successfully matched each individual or group member would earn an entry into a lottery from which we drew three winners of twenty dollars at the conclusion of the experiment. 


\section{Results}

Predicted coordination. We once again calculated $g c$ for all items for both groups and individuals and averaged across all items for each actor. Groups were composed of individuals who had completed the coordination task as individuals. As a result, group responses are not truly independent of individual responses. This design feature means that the performance of individuals and groups are not statistically independent. To address this, we averaged individual performance within each group and conducted a paired samples t-test comparing individual average performance within each group to actual group performance. This test revealed a significant difference, such that groups $(M=.600, S D=.063)$ outperformed individuals $(M=$ $.458, S D=.036), t(20)=13.53, p<.001, \eta^{2}=.90,95 \% C I$ of difference $[.120, .164]$ (Figure 1$)$. These values are almost identical to those obtained in Experiment 1, and provide a replication of the basic intergroup advantage.

Comparison to Nominal Groups. We once again compared the performance of groups to nominal groups. In Experiment 2, individuals were already assigned to groups, and we kept these assignments when assigning individuals to nominal groups. We followed the same nominal group response process used in Experiment 1. We then calculated the likelihood of success on each item for each nominal group and averaged across all items for each actor. An independent samples t-test comparing actual group success $(M=.600, S D=.063)$ to nominal group success $(M=.558, S D=.052)$ revealed a significant actual group advantage, $t(40)=2.38, p=.022, \eta^{2}=$ $.12,95 \%$ CI of difference [.006, .078] (Figure 1). Consistent with Experiment 1, this result suggests that groups outperform what one would expect from simple aggregation of individual responses. Furthermore, we investigated the rate of majority answer adoption in unanimous and two-to-one majority groups and discovered an additional piece of evidence that the intergroup 
advantage does not simply follow from aggregation of individual responses. Unanimous majorities were significantly more likely than simple two-to-one majorities to be adopted by the group $(98 \%$ vs. $87 \%), \chi^{2}(1, N=377)=12.63, p<.001, \varphi=0.18$. If majority responses were being adopted by the group in a rote or mechanical manner, majorities of both types should be equally likely to be adopted by groups.

Focal Points. As a basis for analyses pertaining to the proposed mechanisms underlying the intergroup coordination advantage, we identified the sample focal point as the most commonly selected response for each of the 25 items across all groups and individuals. All focal points can be seen in Table 2. This can also serve as an indicator of coordination performance. Groups responded with the sample focal point on $73 \%$ of all trials while individuals did so $59 \%$ of the time.

Group processes. We were interested in the mechanisms by which groups attained their coordination advantage. The consensual salience hypothesis states that options are likely to be selected if a majority of group members respond with that option as individuals and that majority positions are more likely to be a focal point than non-majority positions. The disjunctive salience hypothesis states that groups will be more likely to select the focal point as their response if one individual in their group selected that option.

Consensual salience. To test for the use of consensual salience we first categorized all 525 group responses ( 25 items by 21 groups) as either having a majority (two or more members giving the same response as individuals) or not (three distinct individual responses). We identified a majority response for approximately two-thirds (377) of the 525 cases. When a majority was present, groups predominantly selected the majority response. All members agreed 
(unanimous majority) in 139 cases, and in these cases they selected the unanimous position $98 \%$ of the time. More interesting are the 238 cases where groups entered deliberations with a simple two-to-one majority. In these instances, groups selected the majority response $87 \%$ of the time. If all three members' responses had an equal chance of being adopted as the group response, the group would be expected to select the majority position $67 \%$ of the time. The observed rate was significantly greater than this "equal-chance" expectation, $\chi^{2}(1, N=238)=42.36, p<.001, \varphi=$ 0.42 .

To assess the effectiveness of selecting a majority response for group coordination, we calculated predicted success, $g c$, for the cases in which the majority response was selected by the group and for cases in which a minority response or response not previously given by any member was selected by the group. When groups selected the majority response, they had a predicted success rate of $64 \%$, compared to $43 \%$ when they selected the minority response and $11 \%$ when they selected a response initially favored by no member. Overall, selecting the majority response led to significantly higher predicted success (64\%) than not selecting it (34\%), $\chi^{2}(1, N=238)=10.92, p<.001, \varphi=0.21$. To summarize, majorities were selected very frequently, and more often than not these majorities made a good choice. These results are consistent with the consensual salience hypothesis. It is important to note however that consensual salience is likely often working in conjunction with disjunctive salience, as focal points (which would have demonstrative appeal) also frequently have majority support within groups. We attempted to disentangle the contributions of both mechanisms in the section below, "Strength in numbers and strength in position."

Disjunctive salience. There were 148 cases for which consensual salience was not applicable because there was no majority; that is, each of a group's members had given a 
different response individually. These cases provide an opportunity to test for the impact of disjunctive salience. The crucial question is to what extent groups adopted the focal response when one of the members had given the focal point as an individual response. There were 108 instances for which only one group member in a group had given the focal response as an individual and there was not a majority. In these instances, the focal point became the group response $67 \%$ of the time. This is much more frequently than would be expected if all three individual responses had an equal chance of being adopted as the group response $(33 \%), \chi^{2}(1, N$ $=108)=54.00, p<.001, \varphi=0.71$. Overall, selecting the focal point led to significantly higher predicted success $(59 \%)$ than not selecting it $(13 \%), \chi^{2}(1, N=108)=20.20, p<.001, \varphi=0.43$. These results support the disjunctive salience hypothesis.

Strength in numbers and strength in position. The foregoing analyses showed that groups tend to adopt the majority position in choosing a response to a tacit coordination problem, and majorities are likely to select the population focal point. Moreover, in the absence of a majority, groups adopted a focal point if it was advocated by only one member. Strength in numbers is at the core of the consensual salience hypothesis. The more people who support a position in a group, the more likely it will prevail as the group decision, and focal points are more likely than other responses to have majority support. Independent of strength in numbers is the idea that some positions are inherently more compelling and more likely to prevail. To further explore these concepts, consider cases in which a group starts with a two-to-one configuration of support. Of these cases (238 in total), the majority position was the focal point in $186(78 \%)$ and a non-focal point option in the remaining $52(22 \%)$. The majority position was more likely to "win" when it was the focal point (91\%) than when the majority response was not a focal point $(69 \%), \chi^{2}(1, N=238)=17.16, p<.001 \varphi=0.27$. Similarly, minorities who 
supported a focal response were more likely to prevail in the group (24\%) than minorities who favored a non-focal response $(7 \%), \chi^{2}(1, N=238)=10.79, p<.01, \varphi=0.21$. These two comparisons underscore the idea that focal points, when considered by the group, have an appeal that goes beyond strength in numbers, as focal majorities are more likely to be selected than nonfocal majorities and focal minorities are more likely to be selected than non-focal minorities. Therefore, disjunctive salience is a unique contributor to group decisions, over and above the impact of consensual salience. To similarly illustrate the unique impact of consensual salience, over and above disjunctive salience, we compiled Table 3, summarizing decision patterns for four group scenarios: 1) one group member supports a focal point and the two other group members support a single non-focal option, 2) one group member supports the focal point and the two other group members support two different non-focal options, 3) a two-person majority supports a focal point, and 4) all three members support a focal point. In all four of these scenarios, the focal point is supported by at least one group member. These scenarios differ only in terms of, and are ordered in terms of, the theoretical strength of consensual salience. Descriptive inspection of Table 3 suggests that focal point adoption rates differ quite dramatically across these four scenarios, suggesting consensual salience augments disjunctive salience when both processes are at play. Indeed, for each scenario the percentage of groups selecting the focal point differs significantly from the preceding scenario. Perhaps the most telling of these comparisons is between scenarios 1 and 3. In both cases the group is comprised of individuals who support two different options: the focal point and some other response. The only difference between these scenarios is the response which is supported by the majority. In scenario 1 the majority supports a non-focal point, while in scenario 3 the majority supports the focal point. Focal point selection is $24 \%$ in scenario 1 and $91 \%$ in scenario 3, a statistically 
significant difference, $\chi^{2}(1, N=213)=56.82, p<.001, \varphi=0.52$. Each increase in the theoretical strength of consensual salience in support of the focal point is associated with a significant increase in focal point selection rates for groups, demonstrating the unique contribution of consensual salience to group decisions.

Focal point strength and relative performance. By analyzing the relative performance of individuals, nominal groups, and actual groups on items which differed in terms of the strength of the population level focal point, we found compelling, if indirect, evidence that these two processes exert their beneficial influence differentially depending on the "difficulty" of the coordination problem. We calculated the correlations between the differences in performance between individuals, nominal groups, and actual groups on each item with the strength of the focal point (operationalized as the percentage of actors selecting the focal point on each item). While there was no correlation between the actual groups' advantage over individuals and focal point strength, $r(25)=.05, p=.81$, comparing each to nominal groups yielded a quite interesting and informative pattern. Nominal groups can be considered the perfect model of consensual salience in action, as they always follow a majority wins decision scheme. We can infer that the extent that actual groups outperform nominal groups is a representation of their use of disjunctive salience, which is best utilized when no majority exists. Furthermore, the magnitude of the nominal groups' advantage over individuals can be seen as quantifying the performance benefit of mechanically utilizing consensual salience. We found a positive correlation between focal point strength and the nominal groups' advantage over individuals, $r(25)=.61, p=.001$. As problems get "easier," meaning as the focal point becomes stronger, nominal groups have a larger performance advantage over individuals, likely because the majority wins decision scheme magnifies a focal point that has strong support in the population from which individuals are 
drawn. Conversely, we found a negative correlation between focal point strength and the actual groups' advantage over nominal groups, $r(25)=-.45, p=.024$. As problems become more “difficult," meaning as the focal point becomes weaker, actual groups have a larger performance advantage over nominal groups. This relationship suggests that disjunctive salience becomes a quite beneficial process when the focal point is a less common response in the population being sampled. In these cases, it is less likely that the focal point will have majority support prior to group deliberation, but still quite possible that a single member will support the focal point, the exact scenario in which disjunctive salience is likely to be most effective. To summarize, when focal points are strong, a consensual process appears sufficient to yield the intergroup advantage, but when focal points are weaker, a disjunctive process is beneficial.

\section{Experiment 3}

One question that remained unanswered by Experiments 1 and 2 was the extent to which this effect is caused solely by coordinating as a group, or also by coordinating with a group. It is possible that a group or individual coordinating with a group would imagine the groups' likely response and, thus, be more inclined to select the focal point, instead of anticipating more idiosyncratic responses of individuals. To the extent that this result is primarily driven by being a member of a group, as is strongly suggested by our process analyses in Experiment 2, simply interacting with a group should yield no discernible coordination benefit. To address this open question, we compared coordination performance in four different scenarios: individuals attempting to coordinate with individuals, individuals attempting to coordinate with groups, groups attempting to coordinate with individuals, and groups attempting to coordinate with groups.

\section{Method}




\section{Participants.}

Participants were 174 students in Introductory Psychology courses at a North American university. They participated in exchange for partial fulfillment of a course requirement, and were assigned to participate as an individual or as part of a three-person group. Every effort was made to assign randomly, but given the extra difficulty of recruiting groups and ensuring that all members attend the experimental session, we ended the study with more individuals than groups. Participants were also randomly assigned to attempt to coordinate their responses with either an individual or a group. This resulted in a 2 (coordination entity: individual or group) by 2 (coordination partner: individual or group) between groups design. Thirty individuals attempted to match another individual, twenty-seven individuals attempted to match a group, nineteen groups attempted to match an individual, and twenty groups attempted to match another group.

\section{Procedure.}

All individuals and groups were given the same coordination task used in Experiments 1 and 2. Half of the individuals and groups were instructed to match their responses with a randomly selected individual from the experiment while the other half were instructed to match their responses with a randomly selected group of three from the experiment. We once again incentivized performance. For each item that was successfully matched each individual or group member would earn an entry into a lottery from which we drew three winners of twenty dollars at the conclusion of the experiment.

\section{Results}

Predicted coordination. We calculated the predicted success for each item for each entity, $g c$, and averaged their predicted success across items. These predicted coordination rates were calculated within each of the four experimental conditions. Predicted success for each 
entity was submitted to a 2 by 2 between groups analysis of variance (ANOVA), which revealed only a significant main effect of coordination entity, $F(1,92)=126.64, p<.001, \eta^{2}$ partial $=.579$. Groups were more successful $(M=.553, S D=.062)$ than individuals $(\mathrm{M}=.418, \mathrm{SD}=.053)$, replicating the pattern of results from the Experiments 1 and 2, and suggesting that performance is enhanced by coordinating as a group. There was no evidence for a main effect of coordination partner, $F(1,92)=0.793 p=.38, \eta_{\text {partial }}^{2}=.009$, or for an interaction between coordination entity and coordination partner, $F(1,92)=.0534, p=.47, \eta^{2}$ partial $=.006$, suggesting that coordination performance is not improved simply by attempting to coordinate with a group.

\section{General Discussion}

These studies show that intergroup coordination is more likely to be successful than interindividual coordination in matching tasks. This advantage is driven by two processes.

Consensual salience derives from the fact that an initial majority in a group is likely to support the focal point in the population. Thus, groups' consensus is likely to converge on a small set of highly efficacious responses. Disjunctive salience derives from the self-evident nature of focal points. If a group member mentions the focal point, it is likely that the focal point will become the group's response.

An extension of these results is that the group advantage should increase with group size. The disjunctive salience hypothesis clearly leads to the prediction that the group advantage increases with group size. This process is identical to the truth-wins model in group problem solving if one assumes that the focal response is akin to "truth" (Laughlin, 1999). The likelihood of the group containing at least one advocate of the "truth" increases as the number of members increases. The consensual salience process is akin to a majority-plurality process in social decision scheme theory (see Stasser, 1999; Davis, 1973). Consider, for example, a majority 
model that gives the benefit of ties to the focal point. Such a model predicts groups will select the focal point if at least half of the members favor it and otherwise will not select the focal point. Given an individual rate of focal point selection of $60 \%$ (comparable to the observed rate of $59 \%$ across all items in our studies), then the probability of a group choosing the focal point increases with group size. For example, as group size goes from three to six, the predicted rate of group endorsement of the focal point goes from $65 \%$ to $82 \%$ (the likelihood of a majority of individuals supporting the focal response in each case). Hence, the intergroup advantage that we observed in three-person groups should be more pronounced in larger groups.

As we have argued, many coordination problems are faced by collectives. Business groups must decide where to locate enterprises such as restaurants and movie theaters. We speculate that this effect is not confined to cases of pure coordination. Many important intergroup interactions are characterized by a mix of conflict and coordination (Abele, Stasser, \& Chartier, 2010). In some public good and resource dilemmas, applying an equal division rule to contributions or harvests is a relatively salient solution that ensures collective success, i.e., a focal point (van Dijk, de Kwaadsteniet, \& de Cremer, 2009). Groups may recognize the presence of coordinated solutions more frequently than individuals, and therefore be more likely to behave in mutually beneficial ways. However, beneficial coordination would only occur to the extent that identification of a coordinated solution would lead to cooperation. The well documented discontinuity effect suggests that groups are generally less cooperative than individuals in social dilemmas (see Wildschut \& Insko, 2007, for a review).

This work furthers our understanding of domains in which group decision making is likely to be efficacious. Tacit coordination appears to be one of a growing list of tasks that can be effectively tackled by harnessing the wisdom of crowds (Surowiecki, 2004). In many 
quantitative forecasting tasks, pooling and averaging the judgments of even just a few individuals can lead to more accurate predictions than are made by individuals (Clemen, 1989; Wolfers \& Zitzewitz, 2004). This effect rests on the fact that individual forecasters differ in terms of their error, and that the error can be "canceled out" by averaging their responses (Larrick \& Soll, 2006). Since tacit coordination is essentially a multi-party social forecasting task, it appears to benefit similarly from such pooling. The uncommon and unsuccessful responses of individuals are likely to be culled from group consideration, leaving prominent (since for many coordination tasks it is not an average), and therefore successful, responses more likely to be selected by the group. A tantalizing possibility of such reasoning is that individuals could potentially tap into these benefits on their own. The so-called crowd within effect occurs when a single person considers a problem several different times and pools their own judgment (Vul \& Pashler, 2008). It is reasonable to expect that such a process could also enhance interindividual tacit coordination.

A boundary condition for our conclusions regarding group superiority is that the coordination problems that we used require matching, not mismatching, of responses to achieve successful coordination. Abele and Stasser (2008) demonstrated that matching and mismatching coordination are different on several dimensions. In general, mismatching problems are more difficult and often require more detailed social knowledge to succeed than do matching problems (Abele, Stasser, \& Chartier, 2014; Chartier \& Abele, 2015). Identifying a popular or salient response for a mismatching task has limited usefulness. Think of the mismatching task of two parties having to pick a different flower from a set of flowers. The shared knowledge that rose is a popular and culturally salient response does not help much in the quest to identify a successful mismatch. In fact, this social knowledge presents a conundrum. It suggests that no one should 
pick rose in a mismatching task, but, if no one else picks rose, then rose is a good response. Thus, it is unclear who, if anyone, should pick rose. As a consequence, neither consensual nor disjunctive salience (in this example, agreeing or recognizing that rose is a popular and culturally prominent flower), would not make the groups any better than individuals in mismatching.

These experiments do not establish whether a minimal level of face-to-face interaction within the coordinating parties is necessary to obtain the intergroup advantage. The effect could simply be due to information exchange within the groups, even in the absence of face-to-face group discussion. In fact, we suspect that such information exchange, simply learning the coordination responses of other individuals without true group discussion, would indeed improve inter-individual coordination. Consensual salience and disjunctive salience, as conceptualized and introduced here, do not assume that groups must discuss and deliberate over a coordination problem for majority support and demonstrative appeal to have their impact.

Overall, the current work clearly demonstrates that groups who must coordinate by matching have an advantage over individuals. Two possible mechanisms were proposed and supported. First, groups tend to choose answers that have majority support, which are likely to be answers that also have majority support in other groups --consensual salience. Second, if one member of a group favors the matching focal point response (i.e., the most popular response in the population), the group is likely to endorse the focal response - disjunctive salience. 


\section{References}

Abele, S., \& Stasser, G. (2008). Coordination success and interpersonal perceptions: Matching versus mismatching. Journal of Personality and Social Psychology, 95, 576-592. doi:10.1037/0022-3514.95.3.576.

Abele, S., Stasser, G., \& Chartier, C. (2014). Social focal points: The use of social information in coordination. Organizational Behavior and Human Decision Processes, 123, 23 - 33. doi:10.1016/j.obhdp.2013.10.005.

Chartier, C., \& Abele, S. (2015). Tacit coordination in close dyads: The use of social focal points. Group Processes and Intergroup Relations, 19(1), 125-134. doi:10.177/1368430215581429.

Clemen, R.T. (1989). Combining forecasts: A review and annotated bibliography. International Journal of Forecasting, 5, 559-583. doi:10.1016/0169-2070(89)90012-5

Davis, J. H. (1973). Group decision and social interaction: A theory of social decision schemes. Psychological Review, 80, 97-125. http://dx.doi.org/10.1037/h0033951.

Diehl, M., \& Stroebe, W. (1987). Productivity loss in idea-generating groups: Toward the solution of a riddle. Journal of Personality and Social Psychology, 53, 497-509.

Feri, F., Irlenbush, B., \& Sutter, M. (2010). Efficiency gains from team-based coordination: Large-scale experimental evidence. American Economic Review, 100, 1892-1912. doi:10.1257/aer.100.4.1892.

Hill, G.W. (1982). Group versus individual performance: are $\mathrm{N}+1$ heads better than one? Psychological Bulletin. 91, 517-539. http://dx.doi.org/10.1037/0033-2909.91.3.517. 
Hinsz, V. B., Tindale, R.S., Nagao, D.H. (2008). Accentuation of information processes and biases in group judgments integrating base-rate and case-specific information. Journal of Experimental Social Psychology, 44, 116-126. doi:10.1016/j.jesp.2007.02.013.

Kerr, N. L., \& Tindale, R. S. (2004) Small group decision making and performance. Annual Review of Psychology, 55, 623-656. doi:10.1146/annurev.psych.55.090902.142009.

Larrick R.P., \& Soll, J.B. (2006). Intuitions about combining opinions: Misappreciation of the averaging principle. Management Science, 52, 111-127. http://dx.doi.org/10.1287/mnsc.1050.0459.

Lattané, B., Williams, K., \& Harkins, S. (1979). Many hands make light the work: The causes and consequences of social loafing. Journal of Personality and Social Psychology, 37, 822-832.

Laughlin, P. R. (1980). Social combination processes of cooperative, problem-solving groups on verbal intellective tasks. In M. Fishbein (Ed.), Progress in social psychology (Vol. 1, pp. 127-155). Hillsdale, NJ: Lawrence Erlbaum.

Laughlin, P. R. (1999). Collective induction: Twelve postulates. Organizational Behavior and Human Decision Processes, 80, 50-69. doi:10.1006/obhd.1999.2854.

Laughlin, P. R., \& Ellis, A. L. (1986). Demonstrability and social combination processes on mathematical intellective tasks. Journal of Experimental Social Psychology, 22, 177-189. doi:10.1016/0022-1031(86)90022-3.

Mehta, J., C. Starmer, \& R. Sugden. (1994). The nature of salience: An experimental investigation of pure coordination games. American Economic Review, 84, 658-673. http://www.jstor.org/stable/2118074. 
Myers, D.G., \& Lamm, H. (1976). The group polarization phenomenon. Psychological Bulletin, 83, 602-627.

Moscovici, S., \& Zavalloni, M. (1969). The group as a polarizer of attitudes. Journal of Personality and Social Psychology, 12, 125-135. http://dx.doi.org/10.1037/h0027568.

Nash, J. (1950). Equilibrium points in n-person games. Proceedings of the National Academy of Sciences, 36, 48-49. http://www.pnas.org/content/36/1/48.full.pdf.

Schelling, T. C. (1960). The strategy of conflict. Cambridge, MA: Harvard University Press.

Stasser G. (1999). The uncertain role of unshared information in collective choice. In L. L. Thompson, J. M. Levine, \& D. M. Messick (Eds.), Shared cognition in organizations: The management of knowledge (pp. 49-69). Hillsdale, NJ: Lawrence Erlbaum Associates, Inc.

Stasser, G. \& Titus, W. (1985). Pooling of unshared information in group decision making: Biased information sampling during discussion. Journal of Personality and Social Psychology, 48, 1467-1478. http://dx.doi.org/10.1037/0022-3514.48.6.1467.

Steiner, I.D. 1972. Group process and productivity. New York City, NY: Academic Press.

Surowiecki, J. (2004). The wisdom of crowds. New York: Doubleday.

Tindale, R.S., Smith, C.M., Dykema-Engblade, A., \& Kluwe, K. (2012). Good and bad group performance: Same process_-different outcomes. Group Processes \& Intergroup Relations, 15, 603-618. doi: 10.1177/1368430212454928. 
van Dijk, E., de Kwaadsteniet, E.W., \& de Cremer, D. (2009) Tacit coordination in social dilemmas: the importance of having a common understanding. Journal of Personality and Social Psychology, 96, 665-678. doi: 10.1037/a0012976.

Vul, E., \& Pashler, H. (2008). Measuring the crowd within: Probabilistic representations within individuals. Psychological Science, 19, 645-647. doi: 10.1111/j.14679280.2008.02136.x.

Wildschut, T. \& Insko, C. A. (2007). Explanations of interindividual-intergroup discontinuity: A review of the evidence. European Review of Social Psychology, 18, 175-211. doi: 10.1080/10463280701676543.

Wolfers, J., \& Zitzewitz, E. (2004). Prediction markets. Journal of Economic Perspectives, 18, 107-126. doi: 10.1257/0895330041371321. 


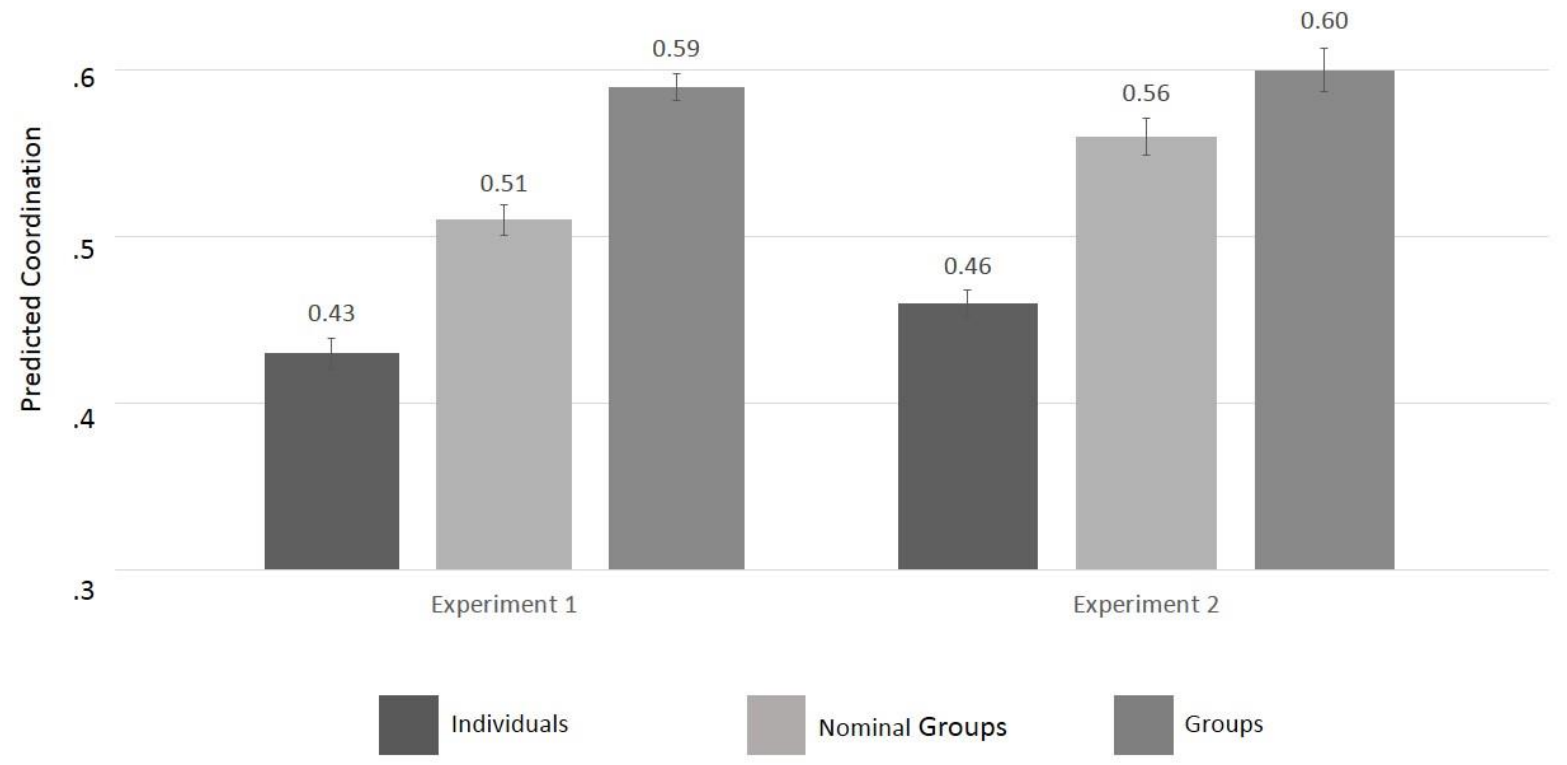

Figure 1. Predicted coordination success $(g c)$ for individuals, nominal groups, and groups in Experiments 1 and 2. 
Table 1.

Coordination Items

\begin{tabular}{|c|c|}
\hline 1 & Write down any year, past, present, or future \\
\hline 2 & Name any flower \\
\hline 3 & Name any car manufacturer \\
\hline 4 & $\begin{array}{l}\text { Write down any date of the year } \\
\text { (day) : }\end{array}$ \\
\hline 5 & Name any US town or city \\
\hline 6 & Write down any positive number \\
\hline 7 & Write down any color \\
\hline 8 & Write down any boy's name \\
\hline 9 & Write down any girl's name \\
\hline 10 & Complete this sentence: A coin was tossed. It came down \\
\hline 11 & $\begin{array}{l}\text { Complete this sentence: The doctor asked for the patient's records. The nurse } \\
\text { gave them to }\end{array}$ \\
\hline 12 & Write down a music genre \\
\hline 13 & Write down a Friday night activity \\
\hline 14 & Choose one of the two: eating in a restaurant or eating a home-cooked meal \\
\hline 15 & Choose a drink: water or soda \\
\hline 16 & Choose a movie genre: action or comedy \\
\hline 17 & Write down a place to exercise \\
\hline 18 & Choose a vehicle: convertible or motorcycle \\
\hline 19 & Write down a sport \\
\hline 20 & Choose an actor: Brad Pitt or Sean Penn \\
\hline
\end{tabular}




\begin{tabular}{|l|l|}
\hline 21 & Choose a swimming spot: beach or pool \\
\hline 22 & Choose a TV show: The Office or Grey's Anatomy \\
\hline 23 & Choose a place to study: library or dorm/house \\
\hline 24 & Choose a pet: dog or cat \\
\hline 25 & Write down a location for a date \\
\hline
\end{tabular}


Table 2.

Focal Points in Experiment 2

\begin{tabular}{|l|r|r|r|}
\hline \multirow{2}{*}{ Question } & Focal Point & \multicolumn{2}{|c|}{$\begin{array}{c}\text { Individual } \% \\
\text { Selected }\end{array}$} \\
\hline 1 & 2011 & $63 \%$ & $71 \%$ \\
\hline 2 & Rose & $81 \%$ & $100 \%$ \\
\hline 3 & Ford & $56 \%$ & $67 \%$ \\
\hline 4 & $12 / 25$ & $29 \%$ & $52 \%$ \\
\hline 5 & Oxford & $52 \%$ & $71 \%$ \\
\hline 6 & 1 & $33 \%$ & $52 \%$ \\
\hline 7 & Blue & $49 \%$ & $43 \%$ \\
\hline 8 & John & $29 \%$ & $62 \%$ \\
\hline 9 & Sarah & $11 \%$ & $19 \%$ \\
\hline 10 & Heads & $75 \%$ & $86 \%$ \\
\hline 11 & Him & $71 \%$ & $90 \%$ \\
\hline 12 & Rap & $37 \%$ & $48 \%$ \\
\hline 13 & Party & $33 \%$ & $52 \%$ \\
\hline 14 & Restaurant & $60 \%$ & $62 \%$ \\
\hline 15 & Water & $86 \%$ & $95 \%$ \\
\hline 16 & Comedy & $83 \%$ & $95 \%$ \\
\hline 17 & The Rec & $51 \%$ & $62 \%$ \\
\hline 18 & Convertible & $87 \%$ & $100 \%$ \\
\hline 19 & Football & $44 \%$ & $57 \%$ \\
\hline 20 & Brad Pitt & $90 \%$ & $100 \%$ \\
\hline 21 & Beach & $78 \%$ & $90 \%$ \\
\hline 22 & The Office & $79 \%$ & $86 \%$ \\
\hline 23 & Library & $67 \%$ & $86 \%$ \\
\hline 24 & Dog & $48 \%$ & $95 \%$ \\
\hline 25 & & & $76 \%$ \\
\hline
\end{tabular}




\section{Table 3.}

Focal Point Selection by Groups across Four Patterns of Individual Responses

\begin{tabular}{|c|c|c|c|c|}
\hline Scenario & $\begin{array}{l}\text { Member } \\
\text { responses }\end{array}$ & $\begin{array}{l}\text { Number } \\
\text { of cases }\end{array}$ & $\begin{array}{l}\text { Percentage of } \\
\text { groups who } \\
\text { selected the focal } \\
\text { point }\end{array}$ & $\begin{array}{l}\text { Statistical comparison to the preceding } \\
\text { scenario above }\end{array}$ \\
\hline 1 & $\begin{array}{l}\text { Focal point } \\
\text { Non-focal point a } \\
\text { Non-focal point a }\end{array}$ & 37 & 24 & -- \\
\hline 2 & $\begin{array}{l}\text { Focal point } \\
\text { Non-focal point a } \\
\text { Non-focal point } b\end{array}$ & 108 & 67 & $\chi^{2}(1, N=145)=20.04, p<.001, \varphi=0.37$ \\
\hline 3 & $\begin{array}{l}\text { Focal point } \\
\text { Focal point } \\
\text { Non-focal point a }\end{array}$ & 186 & 91 & $\chi^{2}(1, N=294)=27.06, p<.001, \varphi=0.30$ \\
\hline 4 & $\begin{array}{l}\text { Focal point } \\
\text { Focal point } \\
\text { Focal point }\end{array}$ & 139 & 98 & $\chi^{2}(1, N=325)=6.71, p<.01, \varphi=0.14$ \\
\hline
\end{tabular}

